\title{
Experimental Study and Numerical Analysis on the Vibration Characteristics of a Terraced Slope along an Embankment Section of a High-Speed Railway
}

\author{
Wujian Yan $\mathbb{D}^{1,2}$ Haizhong Zheng, ${ }^{1}$ Zhijian Wu $\mathbb{D}^{3},{ }^{3}$ Tong $W a n,{ }^{4}$ and Xinxin Tian' \\ ${ }^{1}$ Key Laboratory of Loess Earthquake Engineering, China Earthquake Administration, 450 Donggang West Road, \\ Lanzhou 730000, China \\ ${ }^{2}$ Key Laboratory of Earthquake Engineering and Engineering Vibration, Institute of Engineering Mechanics, \\ China Earthquake Administration, 29 Xuefu Road, Harbin 150080, China \\ ${ }^{3}$ School of Transportation Engineering, Nanjing Tech University, 30 Puzhu South Road, Nanjing 211800, China \\ ${ }^{4}$ School of Civil Engineering, Guangzhou University, Waihuan West Road, Guangzhou 510006, China
}

Correspondence should be addressed to Zhijian Wu; zhijian@njtech.edu.cn

Received 9 February 2020; Revised 21 October 2020; Accepted 2 November 2020; Published 16 December 2020

Academic Editor: Jean-Mathieu Mencik

Copyright (c) 2020 Wujian Yan et al. This is an open access article distributed under the Creative Commons Attribution License, which permits unrestricted use, distribution, and reproduction in any medium, provided the original work is properly cited.

The characteristics of the vibrations induced by the passage of a high-speed train do not only depend on the train speed, axle load, and track irregularity but also depend on the properties of the foundation soil and the surrounding topography. Estimating the vibration characteristics in different terrains is therefore essential. This study investigates the characteristics of propagation and attenuation of the vibrations induced by high-speed trains in loess-terraced slopes. The influence of the soil mechanical properties on the propagation of vibrations is analyzed through a numerical simulation. Field experiments are conducted to measure the vibration induced by a high-speed train at a loess-terraced slope site in Qin'an, Gansu, China. The measured acceleration time history is analyzed in the time domain and frequency domain. The results show that, at the edge of each terrace level, the vibration in the $Y$ direction is the strongest, followed by those in the $X$ and $Z$ directions. The peak ground acceleration values are amplified in all three directions at the fourth terrace level. A model describing the vehicle-roadbed-foundation-terraced slope system is established to study the influence of the elastic modulus of the soil on the vibration characteristics. A change in the elastic modulus of the foundation soil is found to have an evident influence on the horizontal and vertical vibrations in each terrace level. However, a change in the elastic modulus of the soil in a terrace only affects the vibration in that terrace and in the adjacent ones, whereas it has no effect on the vibrations in terraces located farther away. This study can provide some reference values for slope reinforcement along railways.

\section{Introduction}

Railways are important infrastructures and of great significance to the development of society and the improvement of the economy. In recent years, the rapid increase in commercial train speed has made rail travel more convenient, safe, and comfortable. However, the environmental vibration caused by running trains has become increasingly prominent $[1,2]$. Vibrations can cause roadbed settlement, cracking of nearby buildings, and significant noise pollution, leading to serious impacts on the normal life, work, and learning of the surrounding residents $[3,4]$. Evaluating the environmental vibration caused by trains is of great significance for the correct design of shock absorption and isolation measures. However, the environmental vibration caused by trains is an extremely complex problem. Vibrations are affected not only by train speed, axle load, and track irregularity but also by the surrounding soil properties, topography, and other factors. To identify the laws governing the propagation of vibrations induced by trains, many researchers have conducted studies on the causes of train vibration, propagation laws, prediction methods, and 
control methods. These studies can be classified as theoretical, numerical, and field measurement research.

Sheng et al. [5, 6] studied the critical velocity of tracks, the dynamic response characteristics of soil caused by moving loads in layered foundations, and the relationship between the critical velocity and Rayleigh wave velocity of soil. Forrest et al. [7] reduced the track structure to a Timoshenko beam to study the vibration caused by a train. Wang et al. [8] used the finite-element method in the tunnel and the boundary element method in the soil boundary to establish a finite boundary element analysis model, and they proposed a numerical model to predict the free field vibration caused by subway train excitation in a tunnel. Huang et al. [9] established a 2.5D finite-infinite element model of soil vibration caused by subway passage and considered the dynamic characteristics of track irregularity. Triepaischajonsak and Thompson [10] proposed a hybrid modeling method to predict the ground vibration caused by train passage. Ang and Dai [11] used the moving element method to study the response of a nonuniform viscoelastic foundation under a moving load, and they considered the phenomenon of vehicle jump when wheel-rail contact is lost.

Among these approaches, field measurements are the most important. They can not only accurately and scientifically reflect the characteristics of train vibration propagation but also verify the correctness of theoretical and numerical calculations. Xia et al. [12] carried out two field tests on the dynamic responses of railway bridges, ground, and buildings near railways. Their results indicated that the vibration of the ground and buildings increased with an increase in train speed, whereas it attenuated with the distance from the railway lines. Moreover, a vibration amplification area was identified within a certain distance from the railway. Gao et al. [13] studied the ground vibration caused by trains along the Qin-Shen Railway and analyzed the influences of different train formations and speeds on the ground vibration. Meng and Zhou [14] tested the vibration from the Xi-bao highspeed railway in a loess area. Their analysis showed that the horizontal and vertical vibration intensities increased with the train speed and axle load, and the vibration duration increased with the train length. The characteristics of the loess caused the vibration to rebound in some parts. Wang et al. [15] carried out field tests on railway subgrade vibration in different seasons in a seasonally frozen soil region. The results indicated that soil freezing in winter increases the stiffness and strength while decreasing the damping ratio, making the vibration attenuation slower. In the spring and melting seasons, the strength of the soil decreases owing to a large amount of water in the soil (even if the soil is in a saturated state). Thus, the peak acceleration decreases in the vertical direction, whereas it increases slightly in the horizontal direction. Wu et al. $[16,17]$ analyzed the vibration and creep characteristics of soil in a permafrost region subjected to train to load. The results showed that the propagation of the vibration induced by the train from the subgrade was significantly attenuated. The soil undergoes creep deformation under repeated train loads, accumulating a settlement that is largest in the first year of train operation. In addition, a large number of vibration measurements were carried out with respect to the train track, axle boxes of the train [18, 19], and surrounding underground structures [20-23]. However, few studies have addressed the influences of topography and landform along the railway on the characteristics of train vibration propagation.

This study had two main goals. The first was to present in situ measurements obtained in a loess-terraced slope. Based on the measured data, the vibration characteristics of each terrace in the three spatial directions were analyzed in the time and frequency domains. Further discussion is provided regarding the site effect of the terraced slope under the train load. This information has reference value for the reinforcement of slope sites along railway lines and is conducive to the safe and normal operation of trains. The second objective was to use a finite-element numerical model to analyze the influence of the soil parameters of the foundation and each terrace on vibration propagation. As a result, this study revealed the influence law of loess slope vibration under high-speed rail load to provide reference values for slope reinforcement along railways.

\section{Overview of Field Measurements}

The field experiment was performed near the Qin'an Railway Station of the Baoji-Lanzhou High-Speed Rail (Figure 1). The entire length is $400 \mathrm{~km}$, and the designed speed is $250 \mathrm{~km} / \mathrm{h}$. Approximately $75 \%$ of the line is located in the hilly and gully loess region of the Tianli Basin, where the topography and geology are complex, and the collapsible loess layer is thick and has a high grade [24]. The study site is an embankment section. The railway is a China Railway Track System I double-block ballastless track. The site is a typical loess-terraced slope with five levels, and it is mainly composed of backfill material and silty loess. There was no interference from other vibration sources at the study site.

The test point is located in the high-speed railway embankment section at the loess site. One side of the line is flat, and the other side is a terraced slope with five steps. The soil is mainly composed of plain fill and silty loess. Figures 2 and 3 show a detailed illustration of the experimental setup. The front edge of first terrace is $14 \mathrm{~m}$ from the orbit center, its front slope is $1.4 \mathrm{~m}$ high, the slope angle is $80^{\circ}$, and the terrace length is $7.5 \mathrm{~m}$. The second terrace is $3 \mathrm{~m}$ higher than the first terrace, and the length is $5.4 \mathrm{~m}$. The third terrace is $2.6 \mathrm{~m}$ higher than the second terrace, and the length is $7.4 \mathrm{~m}$. The fourth terrace is $2.5 \mathrm{~m}$ higher than the third terrace, and the length is $8.4 \mathrm{~m}$. The fifth terrace is $3.3 \mathrm{~m}$ higher than the fourth terrace. To study the vibration characteristics at each terrace level, the layout scheme for the measuring points was chosen as follows. Five test points were arranged along the direction perpendicular to the railway line. Test point 1 is located at the front edge of the first terrace level, $14 \mathrm{~m}$ away from the track center. Test point 2 is located at the front edge of the second terrace level. Test point 3 is located at the front edge of the third terrace level. Test point 4 is located at the front edge of the fourth terrace level. Test point 5 is located at the front edge of the fifth terrace level.

An 891-II vibrometer, developed by the Institute of Engineering Mechanics (China Earthquake 


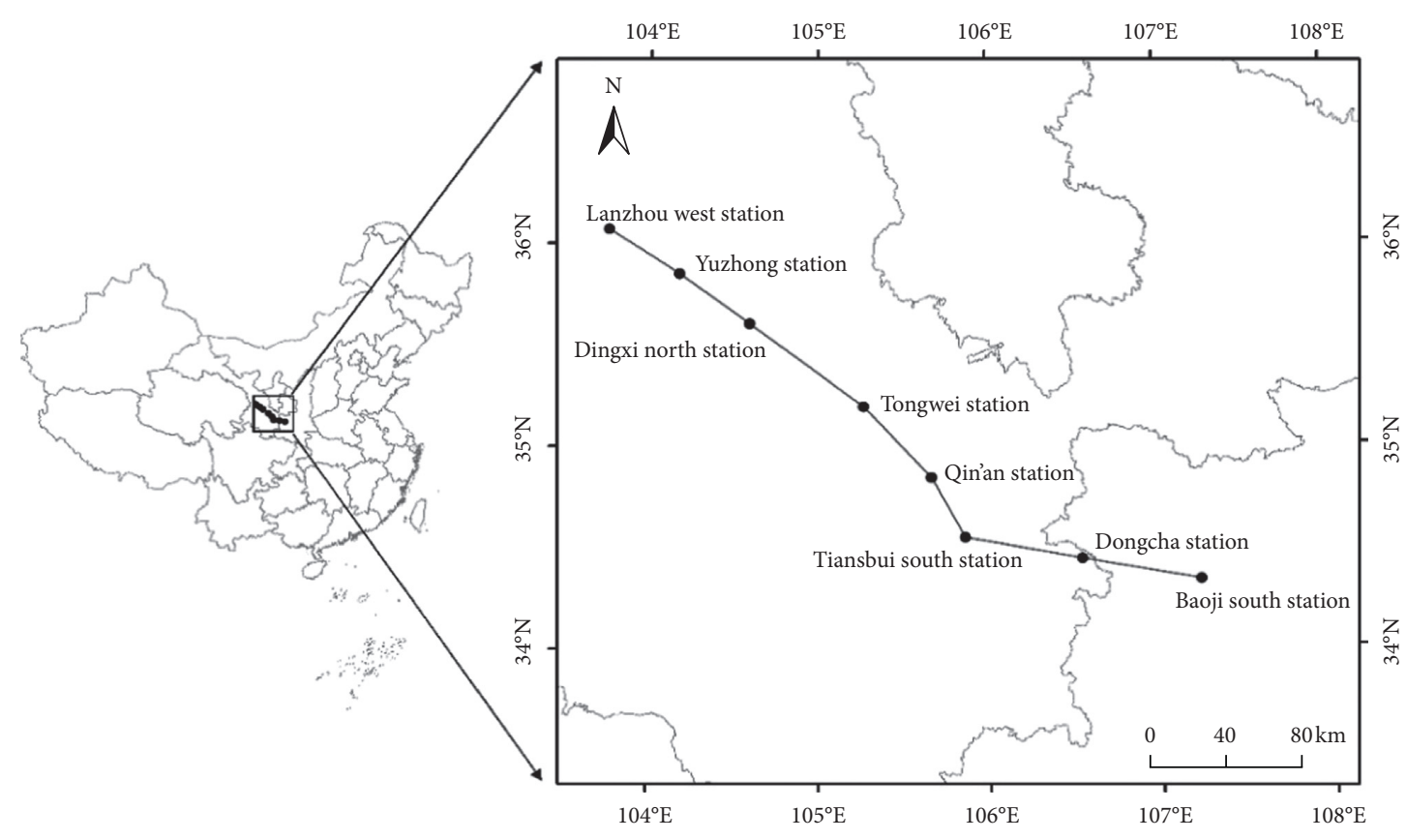

- High-speed rail staion

Figure 1: Location of the test site along the Lanzhou-Baoji line in China.

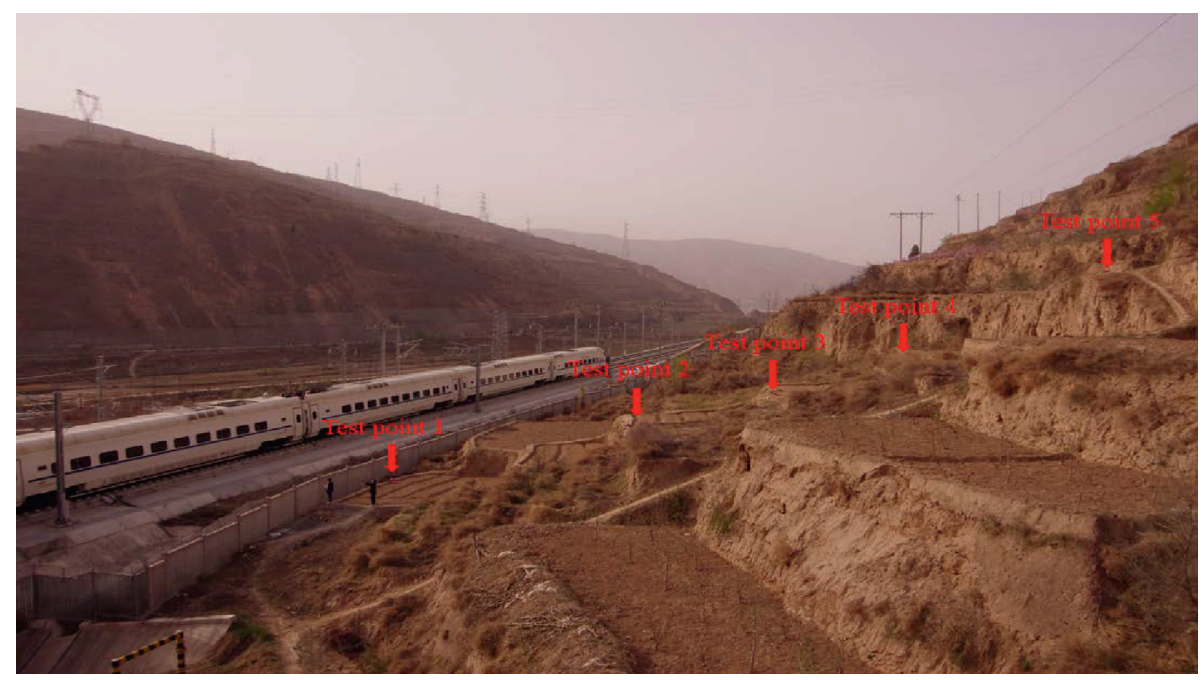

FIgURE 2: Field test overview.

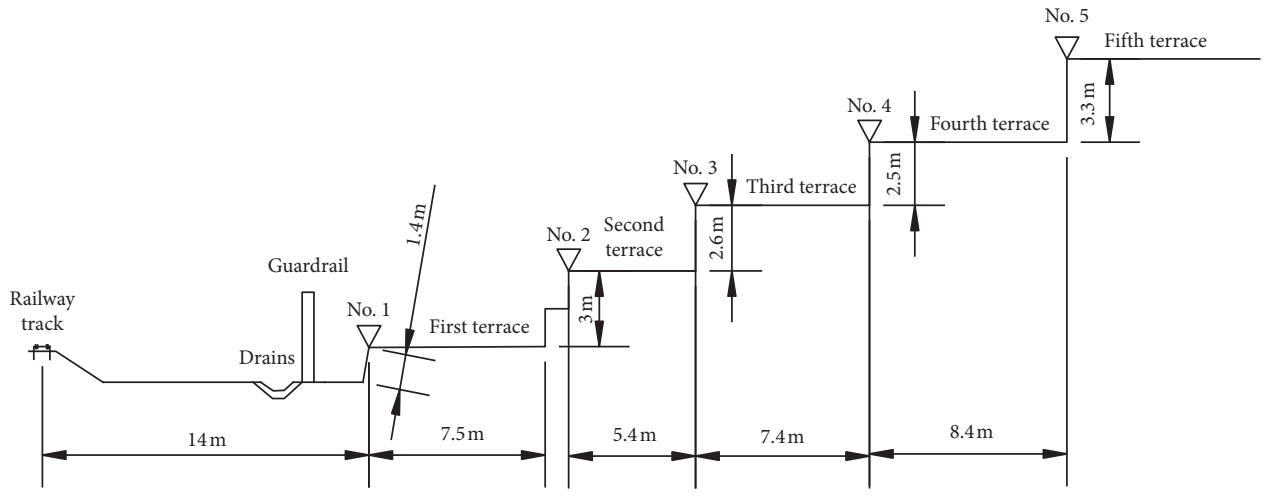

FIGURE 3: Layout of the site observation points. 
Administration), was used to measure the three components of acceleration simultaneously, as shown in Figure 4. The range of the acceleration test was $0-2.0 \mathrm{~g}$. In this test, the horizontal direction $X$ is the direction of train operation, the horizontal direction $Y$ is perpendicular to the railway line, and $Z$ is the vertical direction (i.e., the direction of gravity).

Five CRH2C high-speed trains were employed on-site, and their vibration acceleration time history data were measured by a speed tester. The related parameters of each train are listed in Table 1.

\section{Analysis of Test Results}

3.1. Acceleration Time History. Acceleration data in the three directions at the different test points were collected for train speeds ranging from 201 to $242 \mathrm{~km} / \mathrm{h}$. Figure 5 shows the acceleration time histories of train No. 2 in the three directions at the different test points. It can be seen that the waveform amplitude at each test point increases clearly (by two orders of magnitude) when the train passes. The duration of the vibration signal at the different measuring points remains basically the same, that is, $2-7 \mathrm{~s}$. The acceleration in the three directions at different test points has evident periodic peaks, which are caused by the periodic action of the single bogie of the train. The acceleration time history in the three directions at test point 1 shows evident upper and lower symmetry, and the acceleration peaks of the positive and negative directions are basically the same.

When the train passes, the peak values of acceleration in the $X$ direction at the five measuring points are $36.34,15.74$, $12.14,18.46$, and $16.45 \mathrm{~cm} \cdot \mathrm{s}^{-2}$. The peak values in the $Y$ direction are $74.83,29.82,18.47,20.94$, and $34.87 \mathrm{~cm} \cdot \mathrm{s}^{-2}$. The peak values in the $Z$ direction are $16.02,11.44,11.68$, 13.55 , and $7.90 \mathrm{~cm} \cdot \mathrm{s}^{-2}$. It is evident that the vibration in the $Y$ direction is the strongest, whereas that in the $X$ direction is the second strongest and that in the $Z$ direction is the weakest. This is clearly different from the results obtained on the flat ground [25]. The peak values of acceleration in the three directions rebound at the fourth terrace level. Compared with the vibration at the front edge of the third terrace level, the peak value of acceleration rebounds most evidently in the $X$ direction and less in the $Z$ and $Y$ directions. In addition, the peak value of the acceleration in the $Y$ direction rebounds in the fourth and fifth terrace levels.

\subsection{Frequency Domain Analysis of Vibration Acceleration.} The vibration spectrum can provide information on the frequency content and energy of the signal. Therefore, to study further the vibration characteristics in the different terraces in the three directions, the time-domain data, recorded when train No. 2 passed, were converted into frequency domain data through Fourier transformation. The resulting spectra are shown in Figure 6.

The results show that the frequency spectrum of the vibration induced by the passage of a high-speed train is relatively wide. The frequencies are mainly distributed in the range of $10-80 \mathrm{~Hz}$. The peak value of the spectrum at each test point in the $Y$ direction is the largest, followed by those

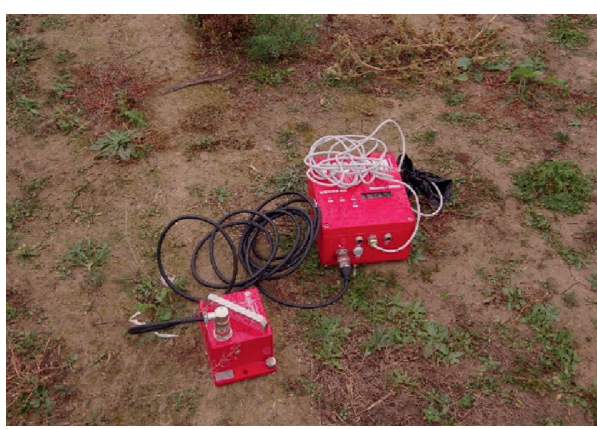

Figure 4: Type 891-II vibrometer.

TABLE 1: Basic parameters of five trains as recorded by the strong motion instrument.

\begin{tabular}{lccc}
\hline Number & Direction & $\begin{array}{c}\text { Speed } \\
(\mathrm{km} / \mathrm{h})\end{array}$ & $\begin{array}{c}\text { Formation } \\
\text { (number of coaches) }\end{array}$ \\
\hline 1 & Baoji to Lanzhou & 201 & 8 \\
2 & Lanzhou to Baoji & 214 & 8 \\
3 & Lanzhou to Baoji & 220 & 8 \\
4 & Lanzhou to Baoji & 242 & 8 \\
5 & Lanzhou to Baoji & 230 & 16 \\
\hline
\end{tabular}

in the $X$ and $Z$ directions. The main frequencies in the three directions at test point 1 are close to $60 \mathrm{~Hz}$. The number of individual peaks in the $Y$ direction is clearly higher than those in the other two directions in the frequency range of 20-60 Hz. This indicates that the vibration energy in the $Y$ direction is more discrete in the frequency distribution. The number of individual peaks in the three directions at test point 2 clearly is higher than those at the other measuring points, indicating that the vibration energy at the second terrace level is dispersed.

In addition, moving away from the railway, in the $X$ direction, the main vibration frequency shifts toward lower values of frequency. In fact, the peak value in the spectrum at test point 4 rebounds at $40 \mathrm{~Hz}$. At test point 5 , there are three peaks at 20 and $40 \mathrm{~Hz}$, and, in the high-frequency range, the peaks also show a rebound phenomenon (Figure (6a)). In the $Y$ direction, the peak value of the vibration spectrum rebounds at test points 3,4 , and 5 , and the main frequency of vibration at test points $1-5$ overall shifts from a high value to a low value. However, the main frequency increases slightly at test point 5 (Figure $6(\mathrm{~b})$ ). In the $Z$ direction, the main frequency of vibration decreases with an increase in the distance from the center of the track. The peak value of the vibration spectrum at test point 4 is amplified at approximately $30 \mathrm{~Hz}$, whereas the peak value of the spectrum at test point 5 decreases rapidly, and the high-frequency component of the vibration is slightly amplified (Figure 6(c)).

The vibration characteristics in the three directions at the edges of different terraces are different. The difference in vibration in the $Y$ direction is the greatest, and the vibration in that direction is the strongest. This shows that not only the characteristics in the $Z$ direction but also those in the horizontal direction should be considered when studying the influence of different topographies and landforms on vibration. 


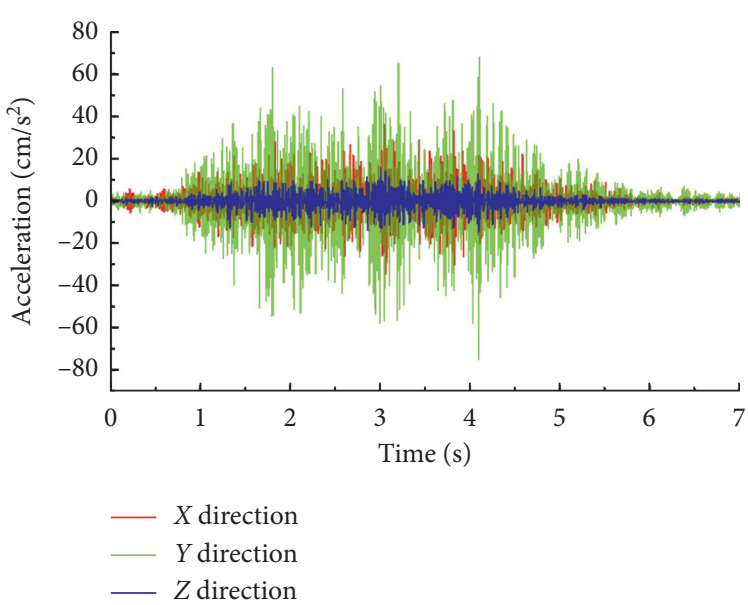

(a)

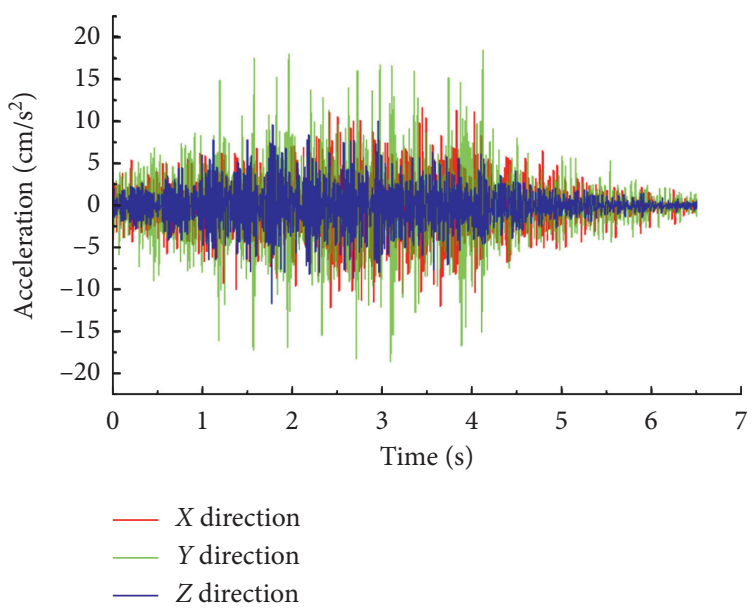

(c)

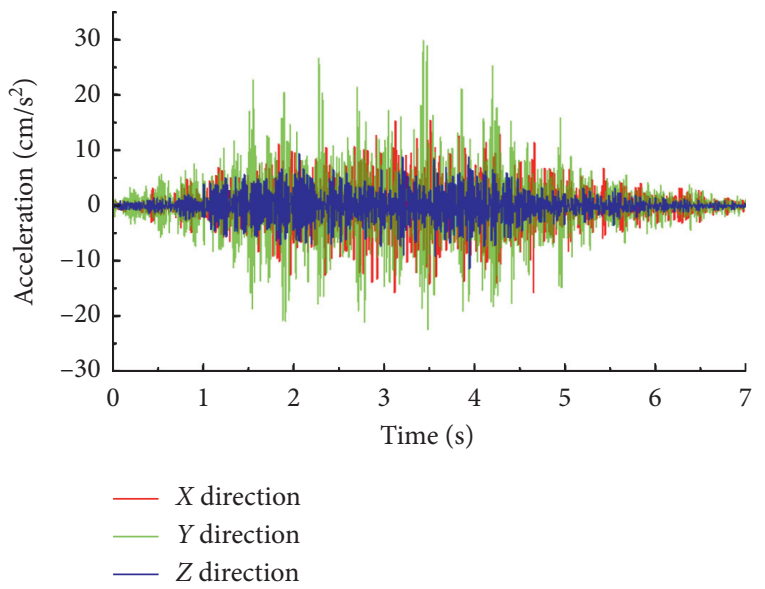

(b)

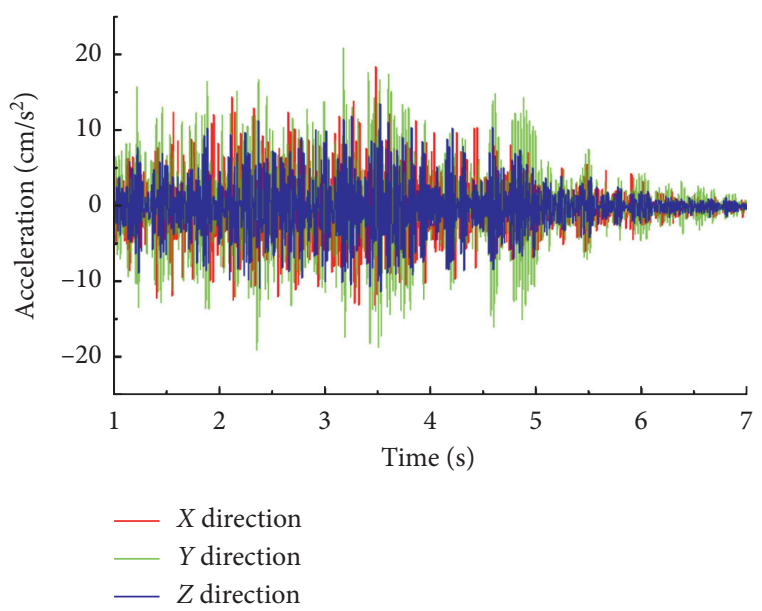

(d)

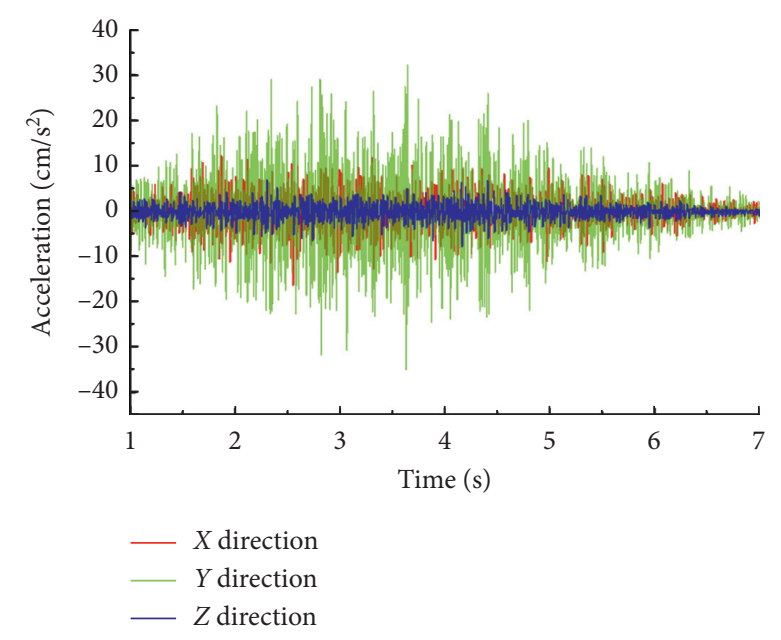

(e)

Figure 5: Acceleration time history curve of different test points when train no. 2 passed. (a) No. 1. (b) No. 2. (c) No. 3. (d) No. 4. (e) No. 5.

3.3. Influence of Train Speed on Vibration Propagation. The acceleration in the vibration signal (i.e., its second derivative) is the main information used for calculating the subgrade settlement, slope instability, and track deformation caused by a train load. The environmental vibration caused by train operation is mainly evaluated from the acceleration of the vibration signal, according to the stipulations of the "Measurement Method of Environmental Vibration in Urban Areas" [26]. Therefore, in this study, the peak value of acceleration $\left(a_{\max }\right)$ and the acceleration level (VAL, in 


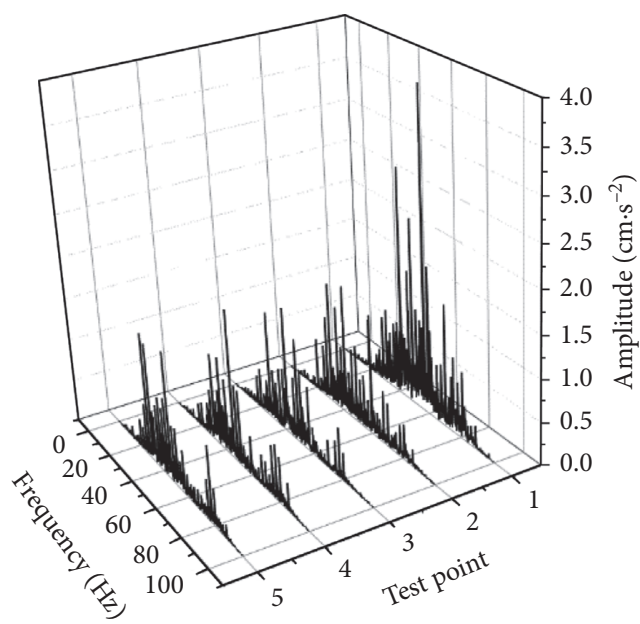

(a)

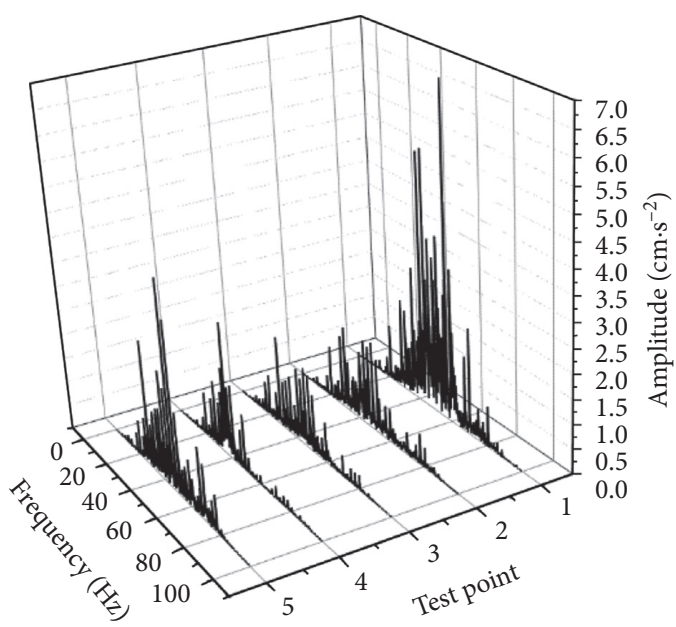

(b)

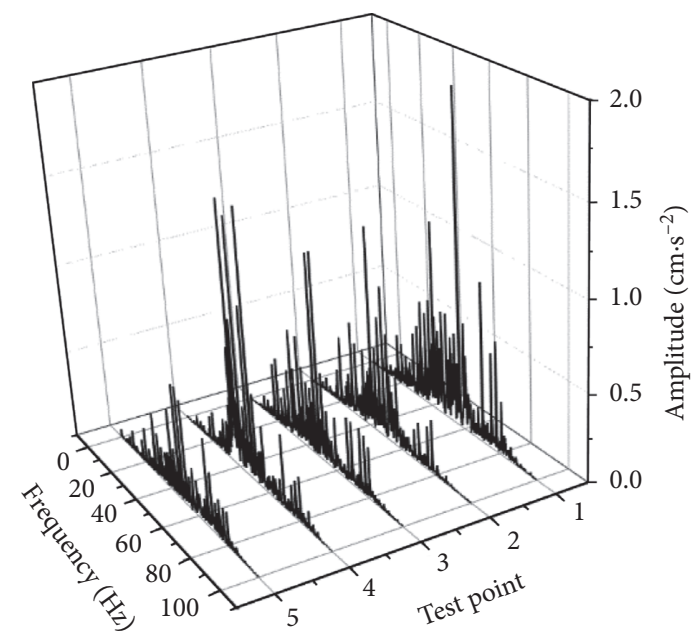

(c)

Figure 6: Acceleration spectra in the three directions at different test points when train no. 2 passed. (a) $X$ direction. (b) $Y$ direction. (c) $Z$ direction.

decibels) were used to analyze the influence of train speed on the vibration in each terrace. The mathematical expressions are

$$
\begin{aligned}
a_{\max } & =\max \left(\left|a_{i}\right|\right), \\
\mathrm{VAL} & =20 \lg \frac{a}{a_{0}}, \\
a & =\frac{1}{n} \sqrt{\sum_{i=1}^{n} a_{i}^{2},}
\end{aligned}
$$

where $a_{i}$ is the acceleration of the $i$ th sampling point, $a$ is the effective value of acceleration $\left[\mathrm{m} / \mathrm{s}^{2}\right], a_{0}$ is the effective value of the reference acceleration (i.e., $10^{-6} \mathrm{~m} / \mathrm{s}^{2}$ ), and $n$ is the number of sampling points.

The influence of train speed on the vibration characteristics in the three directions was analyzed by selecting trains nos. 2, 3, and 4 with the same running direction and carriage formation, as shown in Figures 7-9. The time trend of the peak acceleration and the level of acceleration are basically the same in the three directions for the first three test points; that is, they exhibit a trend of attenuation with an increase in the distance from the railway center and an increase with the increase in train speed. In contrast, the time trend of the peak acceleration and the acceleration levels for test points 4 and 5 vary with the train speed and are different in the three directions.

As shown in Figure 7 ( $X$ direction), amplification of the vibration occurred at test points 4 and 5 . When the train speed was $214 \mathrm{~km} / \mathrm{h}$, the amplification at test point 4 was the strongest, and the peak acceleration and acceleration levels were the largest (i.e., larger than those at 220 and $242 \mathrm{~km} / \mathrm{h}$ ). One possible reason for this phenomenon is that the Rayleigh wave velocity at the fourth terrace was similar to that of the train; thus, resonance occurred.

As shown in Figure 8 ( $Y$ direction), the vibration at test points 4 and 5 was amplified, and amplification was especially evident at test point 5 . When the train speed was 


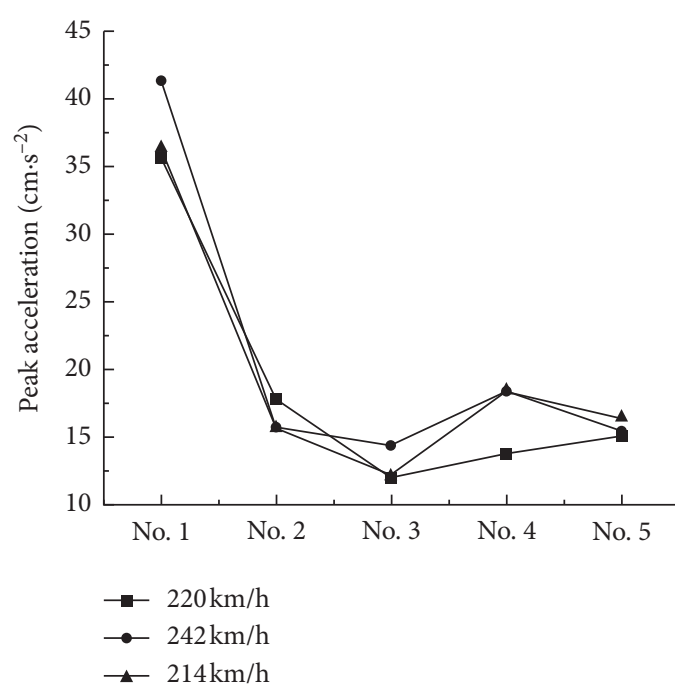

(a)

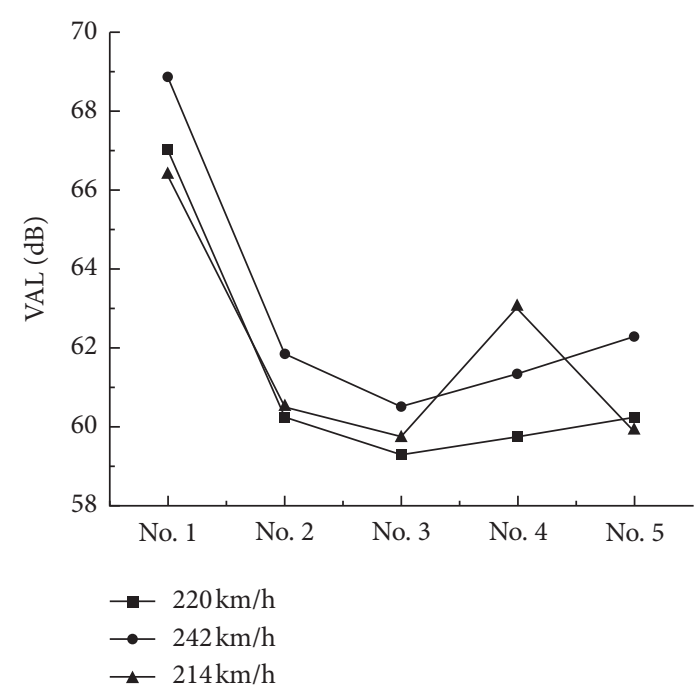

(b)

Figure 7: Peak acceleration in $X$ direction and VAL at five test points as a function of train speed. (a) Peak acceleration. (b) Vibration acceleration level.

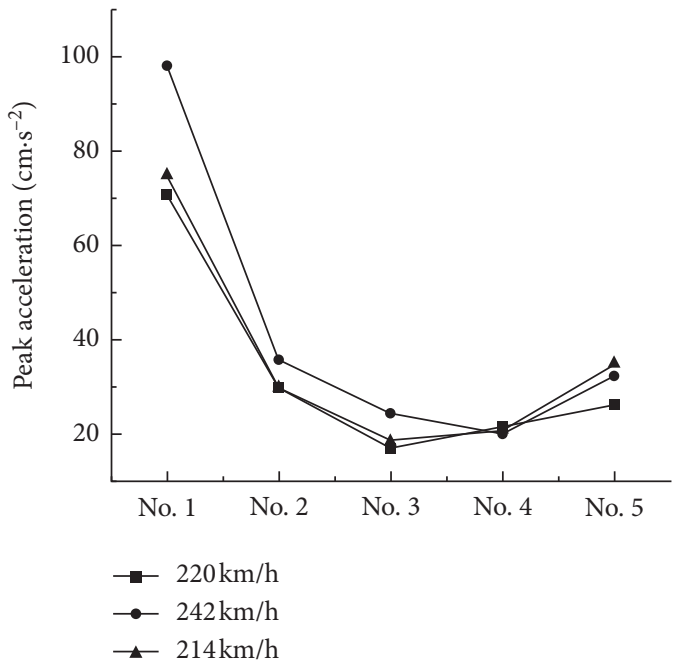

(a)

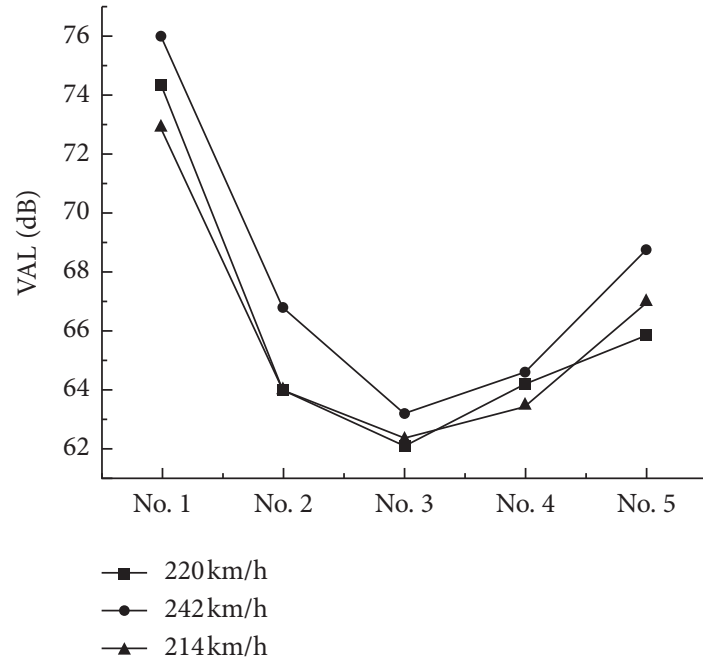

(b)

Figure 8: Peak acceleration in $Y$ direction and VAL at five test points as a function of train speed. (a) Peak acceleration. (b) Vibration acceleration level.

$214 \mathrm{~km} / \mathrm{h}$, the peak acceleration at test point 5 was the largest. However, when the train speed was $242 \mathrm{~km} / \mathrm{h}$, the acceleration level at test point 5 was the largest. This indicates that when the train speed increased, the vibration intensity also increased, but the peak acceleration did not necessarily increase with the increase in train speed.

As shown in Figure 9 ( $Z$ direction), the vibration at test point 4 was amplified, while the vibration at test point 5 decreased rapidly. When the train speed was $214 \mathrm{~km} / \mathrm{h}$, the peak acceleration at test point 4 was the largest, larger than that induced by the other trains. The acceleration level at test point 4 was the largest when the train speed was $242 \mathrm{~km} / \mathrm{h}$, followed by those at 214 and $220 \mathrm{~km} / \mathrm{h}$. This suggests that resonance occurred at the fourth terrace when the train speed was $214 \mathrm{~km} / \mathrm{h}$. With the increase in the train speed, the resonance decreased, and the vibration intensity was mainly controlled by the train speed.

\section{Numerical Analysis of Vibration}

A finite-element model of the terraced slope was established using the finite-element software ABAQUS in accordance with the actual field test conditions. The vibration characteristics of the terraced slope under a high-speed train load were scientifically calculated and evaluated.

Figure 10 is a schematic diagram of the vibration propagation path in terraced slopes under train loads. During train operation, the vibration is mainly caused by the 


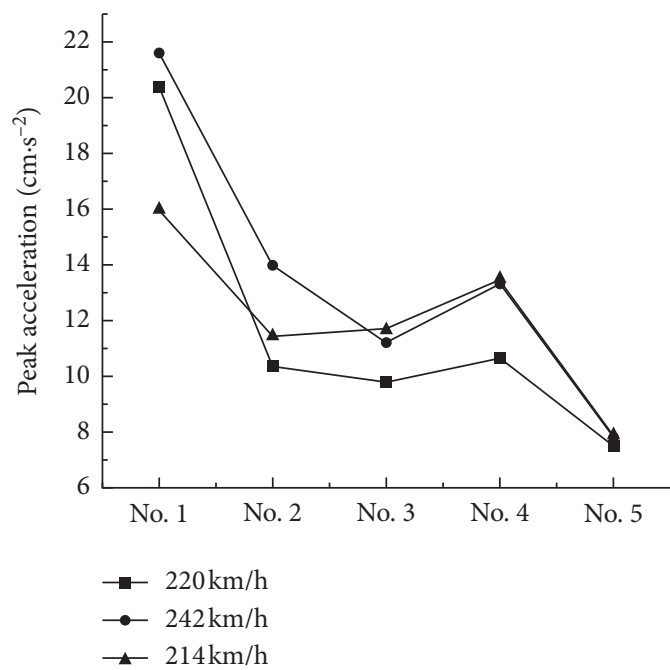

(a)

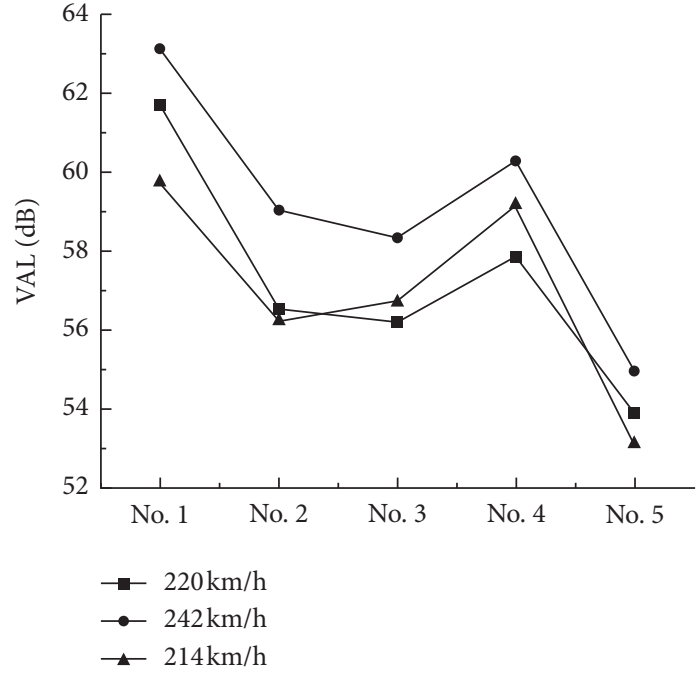

(b)

Figure 9: Peak acceleration in $Z$ direction and VAL at five test points as a function of train speed. (a) Peak acceleration. (b) Vibration acceleration level.

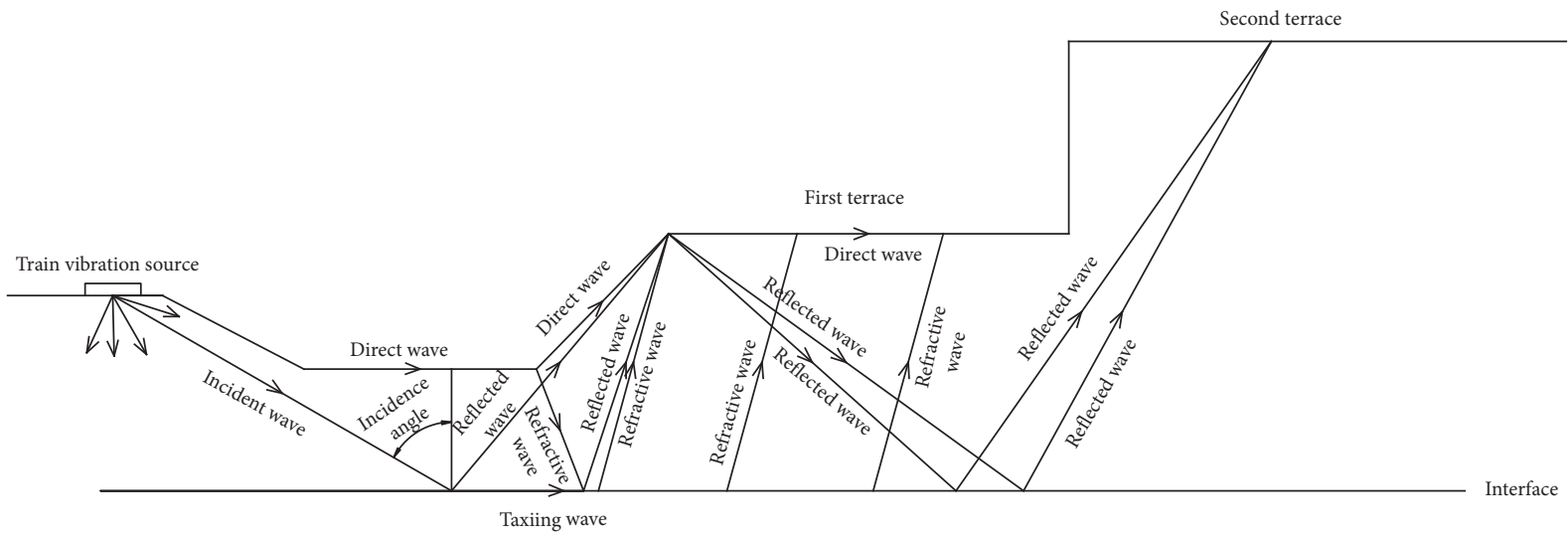

Figure 10: Process of vibration propagation in a terraced slope.

train axle load and track irregularity. It propagates from the track to the roadbed in the form of a vibration wave and then to the surrounding soil. When the incident angle of the vibration wave is less than its critical angle, the incident wave only generates a reflection wave at the interface. When the incident angle is larger than the critical angle, a refraction wave is also generated. The reflected and refracted waves propagate to the edge of the first terrace field and then produce a reflected wave, which in turn produces a reflected wave when it reaches the interface. Similarly, the direct wave produces a refraction wave at the bottom of the slope of the first terrace level. Then, the refraction wave arrives at the interface and produces a reflection wave that reaches the edge of the first terrace level. The reflection wave is reflected at the interface. Therefore, the vibration in each terrace is mainly caused by the interactions of the direct, reflected, and refracted waves. The wave propagation is mainly influenced by the velocity and thickness of the site, and the velocity is directly related to the elastic modulus of the soil at the site [27]. Based on the above analysis, a numerical model was established for foundations and terraces with different elastic modulus values to analyze the effects of the soil wave velocity on vibration propagation.

\subsection{Numerical Calculation}

4.1.1. Train Load. When a train is running on a track, considering the influence of the wheel-axle static load and track irregularity, the vertical load $F(t)$ of the train can be expressed as [28]

$$
F(t)=p_{0}+p_{1} \sin \left(\omega_{1} t\right)+p_{2} \sin \left(\omega_{2} t\right)+p_{3} \sin \left(\omega_{3} t\right) .
$$

Here, $p_{0}$ is the static load of the axle, $p_{1}$ is the vibration load caused by the vehicle irregularity, $p_{2}$ is the dynamic additional load acting on the line, and $p_{3}$ is the waveform abrasion vibration load:

$$
p_{i}=M_{0} \cdot \alpha_{i} \cdot \omega_{i}^{2} \cdot(1,2,3),
$$


where $\alpha_{i}$ is the typical vector height (the value is shown in Table 1), $M_{0}$ is the mass under the spring of the train, and $\omega_{i}$ is the wavelength frequency of irregular vibration at different speeds (the value is shown in Table 2):

$$
\omega_{i}=\frac{2 \pi v}{L_{i}(i=1,2,3)} .
$$

Here, $v$ is the train speed and $L_{i}$ is the typical wavelength, the values of which are shown in Tables 1 and 2.

According to the axle load required for Chinese railways, a single static wheel weight $p_{0}=80 \mathrm{kN}$ and a mass $M_{0}=750 \mathrm{~kg}$ are used. The typical irregular vibration wavelength and corresponding vector height are determined by the power spectrum of the track irregularity of British railways.

Within the scope of the train load, the vertical load acting on the subgrade is equivalent to the vertical load $F_{\text {ave }}(t)$ distributed uniformly along the line. The calculation formula for $F_{\text {ave }}(t)$ is as follows [29]:

$$
F_{\text {ave }}(t)=\frac{K \cdot n \cdot N \cdot F(t)}{l} .
$$

In this equation, $K$ is a correction factor, $n$ is the wheelset number of each carriage, $N$ is the train carriage formation, and $l$ is the train length.

The vertical load generated by the train at $242 \mathrm{~km} / \mathrm{h}$ is shown in Figure 11.

4.1.2. Finite-Element Model of Terraced Slope. According to a survey of the field measurements and design requirements for a high-speed railway, a two-dimensional numerical calculation model was established, as shown in Figure 12. Because the maximum running speed of the train recorded in this test was $242 \mathrm{~km} / \mathrm{h}$, the faster the train speed, the stronger the vibration. Therefore, in this study, a running speed of $242 \mathrm{~km} / \mathrm{h}$ was selected to calculate the train load.

The model is divided into two parts. The first part is the subgrade, which is composed of a $0.4 \mathrm{~m}$ subgrade surface, $2.3 \mathrm{~m}$ subgrade bottom, and $3.6 \mathrm{~m}$ subgrade foundation. The second part comprises the foundation and terraced levels.

To prevent wave reflection, an infinite element boundary is used at both the left and right boundaries and at the bottom of the model. The deformation of the subgrade and the surrounding soil is within the range of elastic deformation owing to the small deformation of these regions under the train load. The mechanical parameters for these regions and the soil are listed in Table 3.

In the modeling process, first, gravity calculation is carried out for the model. Then, in situ stress balance is performed. The train load is equivalent to the linear uniform load acting on the subgrade surface for dynamic calculation.

4.2. Numerical Results. Gu et al. [31] studied the deformation of a loess slope under cyclic loading in Shanxi Province and found that the dynamic elastic modulus of loess decreases gradually with the increase in dynamic strain, and the dynamic elastic modulus of loess under different
TABle 2: Typical irregular vibration wavelengths and corresponding vector heights.

\begin{tabular}{ccc}
\hline$i$ & Wavelength $(L / \mathrm{m})$ & Sagittal height $(\alpha / \mathrm{mm})$ \\
\hline 1 & 10 & 3.5 \\
2 & 2 & 0.4 \\
3 & 0.5 & 0.08 \\
\hline
\end{tabular}

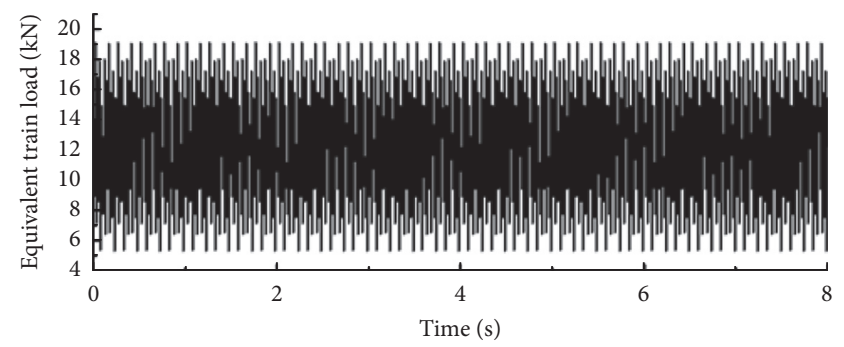

FIgURE 11: Vertical load induced by a train running at $242 \mathrm{~km} / \mathrm{h}$.

confining pressures is between 5 and $62 \mathrm{MPa}$. An et al. [30] studied the correlation degree between the microparameter index and the dynamic elastic modulus of loess, and they found that the dynamic elastic modulus of loess at different depths is between 27.8 and $172 \mathrm{MPa}$ in Gansu Province. Therefore, the elastic modulus of loess in Northwest China is mainly between 5 and $172 \mathrm{MPa}$. In this study, the effect of every $30 \mathrm{MPa}$ increase in the elastic modulus of the foundation and the terraced soil on vibration propagation was analyzed. In other words, the peak accelerations of the measuring points were compared and analyzed when the elastic modulus of the soil was $15,45,75$, and $105 \mathrm{MPa}$.

To compare the peak values of the horizontal and vertical accelerations at each terrace level, test points A-E were arranged at the edge of each terrace level, and the calculation results are shown in Figures 13-18.

When the elastic moduli of the foundation and the first to fourth terraced levels are $15 \mathrm{MPa}$ and that of the fifth terraced field is $45 \mathrm{MPa}$, the simulated peak values of acceleration at the edge of each terrace are consistent with the measured results shown in Figure 18, which proves the correctness and feasibility of the numerical model.

Figure 13 shows the influence of the elastic modulus of the foundation soil on the vibration propagation. The peak value of the horizontal acceleration at each test point decreases with an increase in the elastic modulus of the foundation. Moreover, with the increase in the elastic modulus, the rebound phenomenon of the peak value of the horizontal acceleration at the edge of the fifth terrace is weaker. The peak value of the vertical acceleration decreases with the distance from the center of the track, and there is no amplification at the edge of each terrace when the elastic modulus of the foundation is $15 \mathrm{MPa}$. With the increase in the elastic modulus of the foundation soil, the peak value of the vertical acceleration at test points $\mathrm{A}, \mathrm{C}, \mathrm{D}$, and $\mathrm{E}$ decreases. However, the peak value of the vertical acceleration at test point $B$ increases with the increase in the elastic modulus of the foundation in a certain range, and the phenomenon of vibration rebound becomes more evident. It 


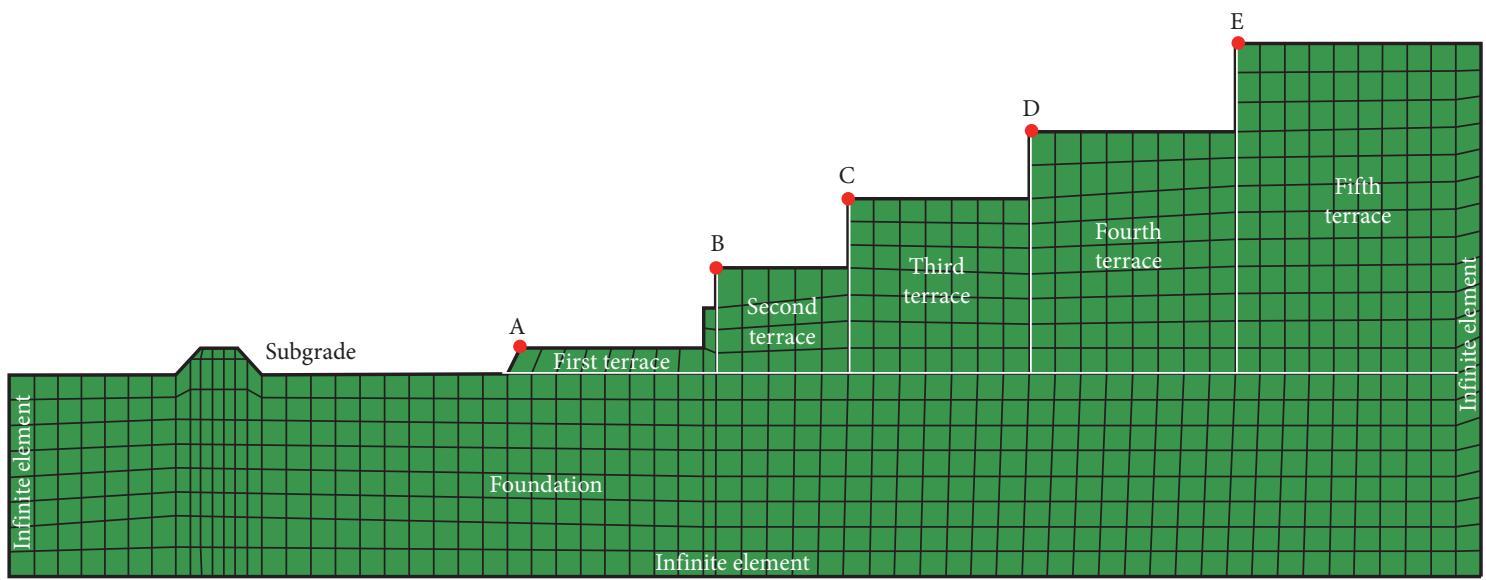

Figure 12: Numerical model.

TABLE 3: Subgrade and soil parameters [30].

\begin{tabular}{lcccc}
\hline Name & Elastic modulus $(\mathrm{MPa})$ & Poisson's ratio & Damping ratio & Density $\left(\mathrm{kg} / \mathrm{m}^{3}\right)$ \\
\hline Bedding surface & 150 & 0.25 & 0.02 & 1900 \\
Bedding bottom & 110 & 0.25 & 0.02 & 1900 \\
Subgrade foundation & 50 & 0.3 & 0.03 & 1800 \\
Soft & 15 & 0.3 & 0.03 & 1500 \\
\hline
\end{tabular}

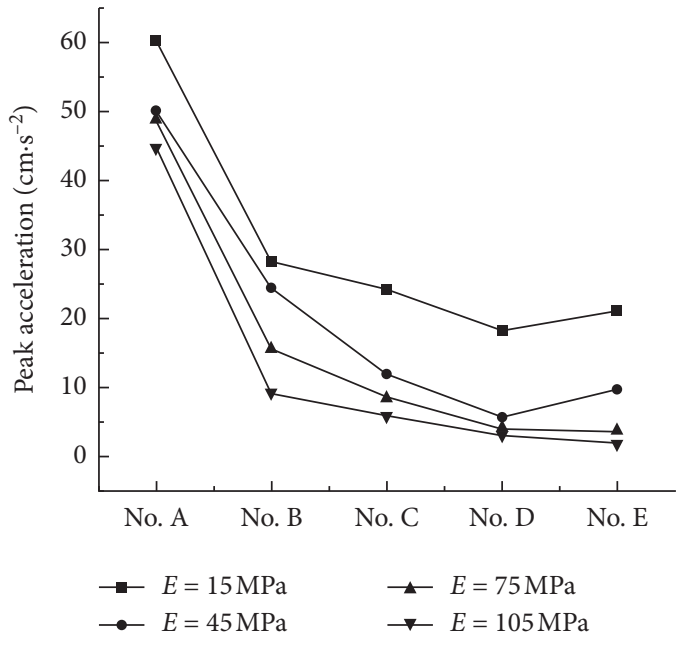

(a)

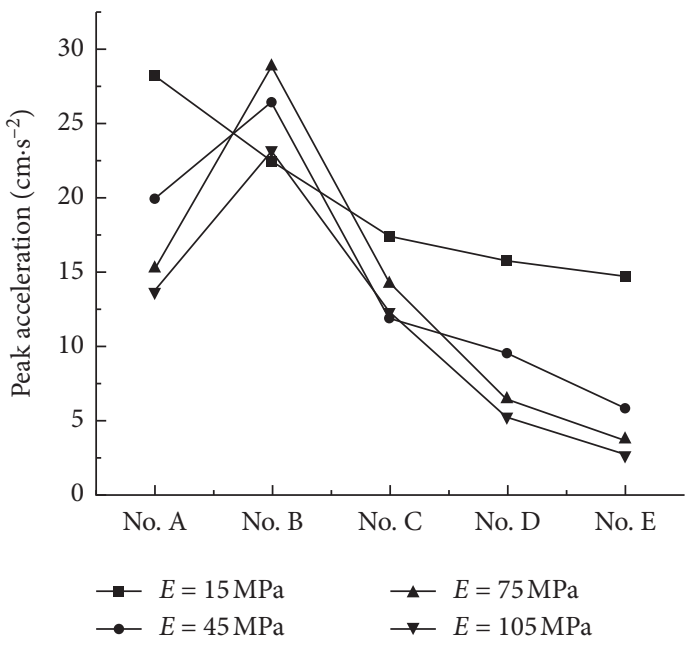

(b)

FIGURE 13: Influence of the elastic modulus of the foundation on peak acceleration. (a) Horizontal direction. (b) Vertical direction.

may be that the Rayleigh wave velocity of the soil is close to the vibration propagation velocity under the elastic modulus, which causes the resonance of the soil, so the peak acceleration of point $B$ increases.

Figure 14 shows the effect of the elastic modulus of the soil in the first terraced field on the characteristics of vibration propagation. The results show that, with an increase in the elastic modulus of the soil in the first step field, the peak value of the horizontal acceleration at test point $\mathrm{A}$ decreases, and the peak values of the horizontal acceleration at test points $\mathrm{B}$ and $\mathrm{C}$ increase. However, there is little effect on the peak values of the horizontal acceleration at test points $D$ and $E$. In the vertical direction, with the increase in the elastic modulus of the soil at the first terrace level, the peak value of the acceleration at test points $A, D$, and $E$ decreases, but the peak value of the acceleration at test point $\mathrm{B}$ increases, and the vibration rebound becomes more evident. Moreover, there is little impact on the peak value of acceleration at test point $C$. Because the first step field is far from the third step field, the change in the elastic modulus of the first step field does not cause a change in the peak acceleration at point $\mathrm{C}$.

Figure 15 shows the effect of the elastic modulus of the soil of the second terrace on the characteristics of vibration propagation. In the horizontal direction, with an increase in the elastic modulus of the soil in the second terrace level, the 


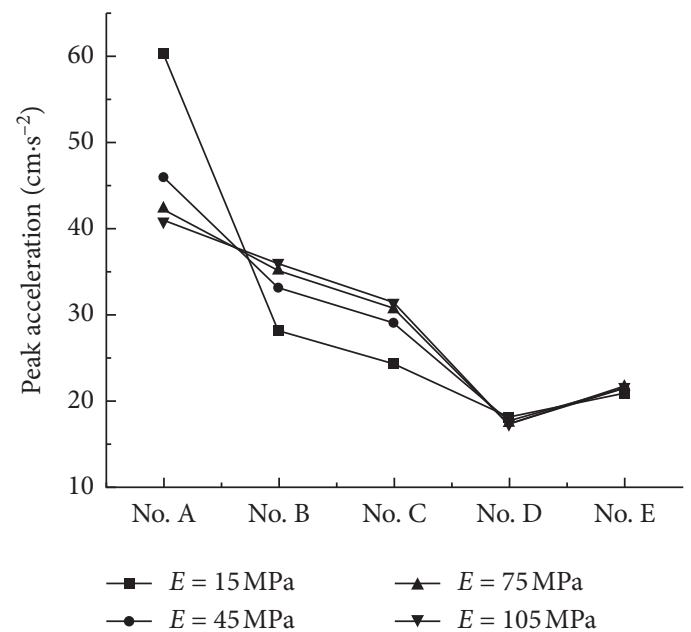

(a)

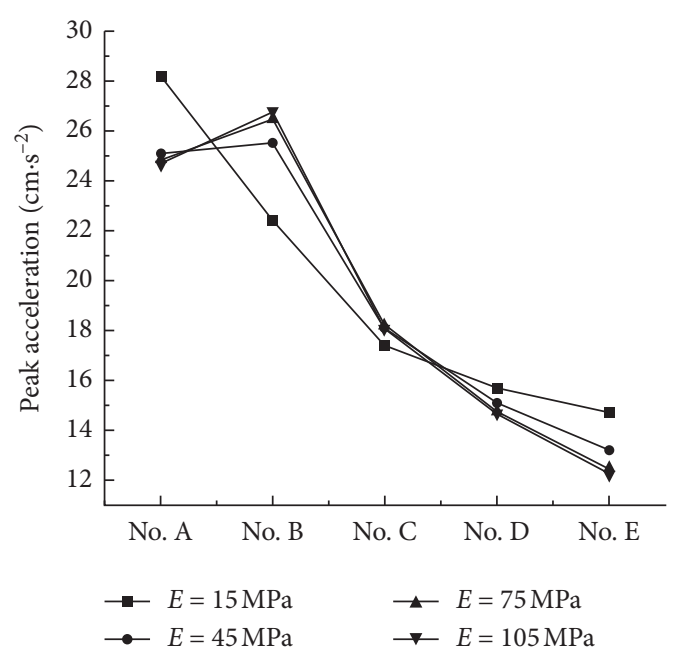

(b)

Figure 14: Influence of the elastic modulus of the first terrace on vibration. (a) Horizontal direction. (b) Vertical direction.

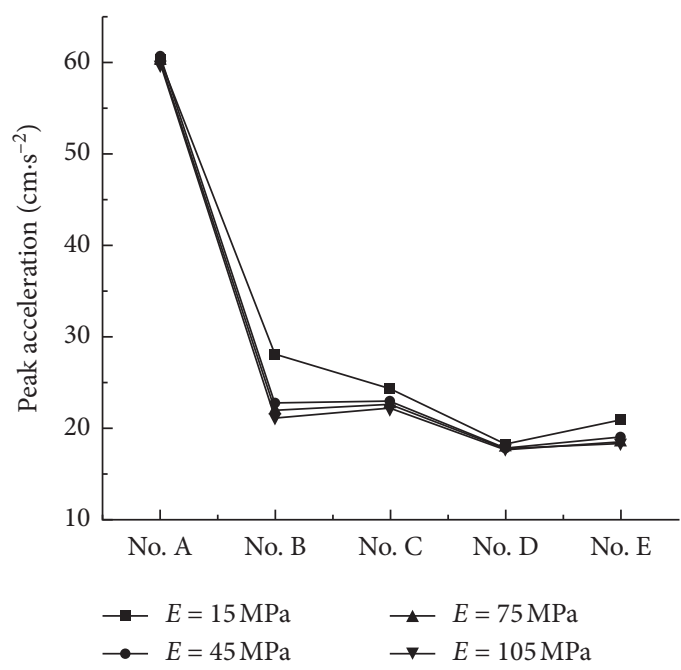

(a)

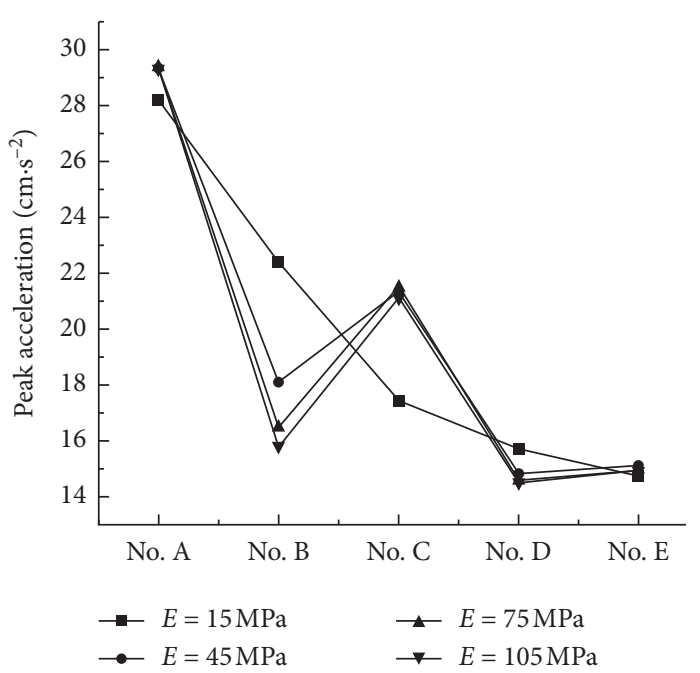

(b)

FIGURE 15: Influence of the elastic modulus of the second terrace on vibration. (a) Horizontal direction. (b) Vertical direction.

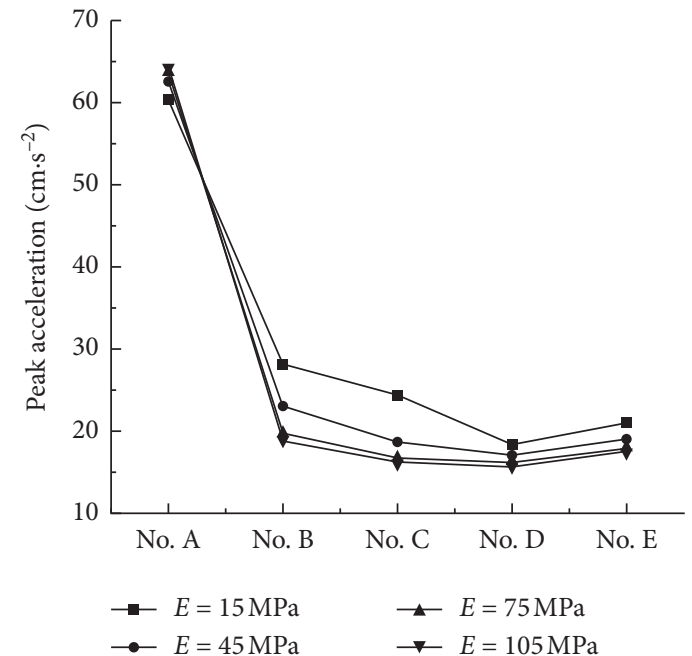

(a)

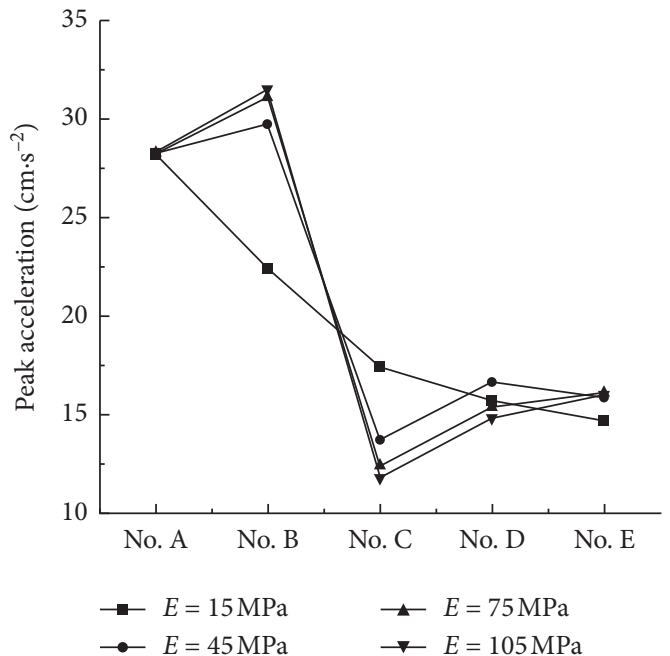

(b)

Figure 16: Influence of elastic modulus of the third terrace on vibration. (a) Horizontal direction. (b) Vertical direction. 


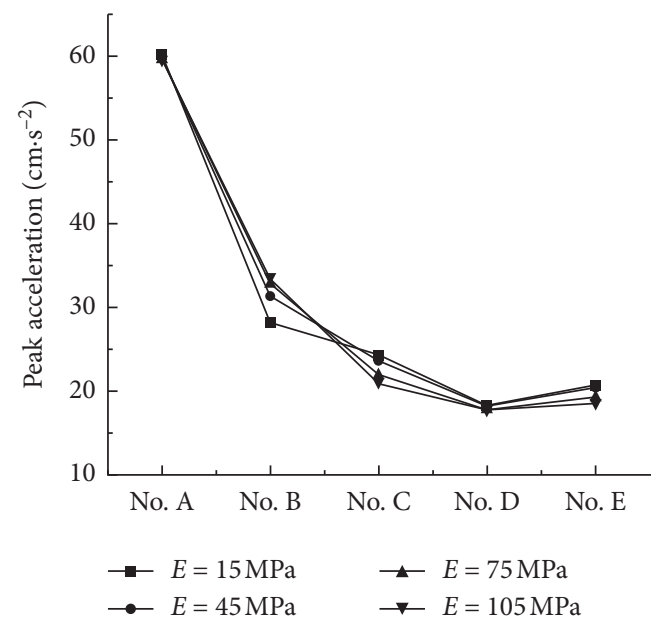

(a)

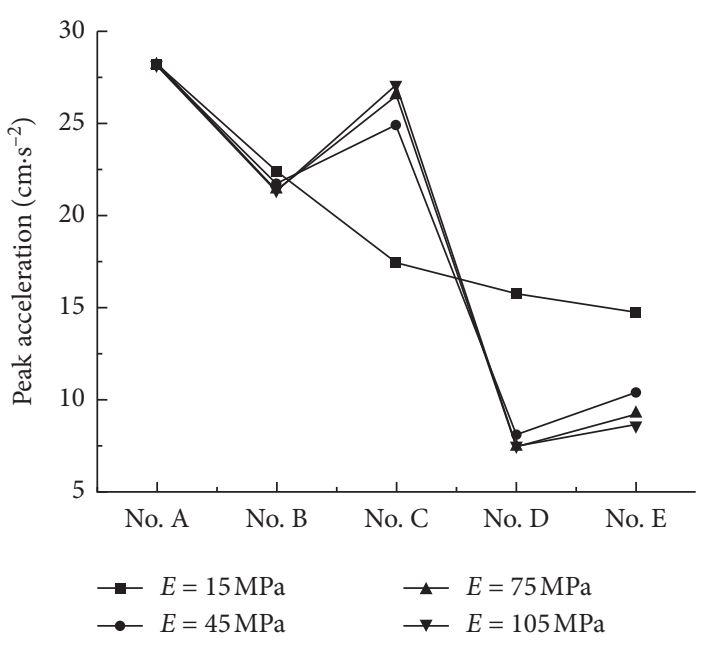

(b)

FIGURE 17: Influence of the elastic modulus of the fourth terrace on vibration. (a) Horizontal direction. (b) Vertical direction.

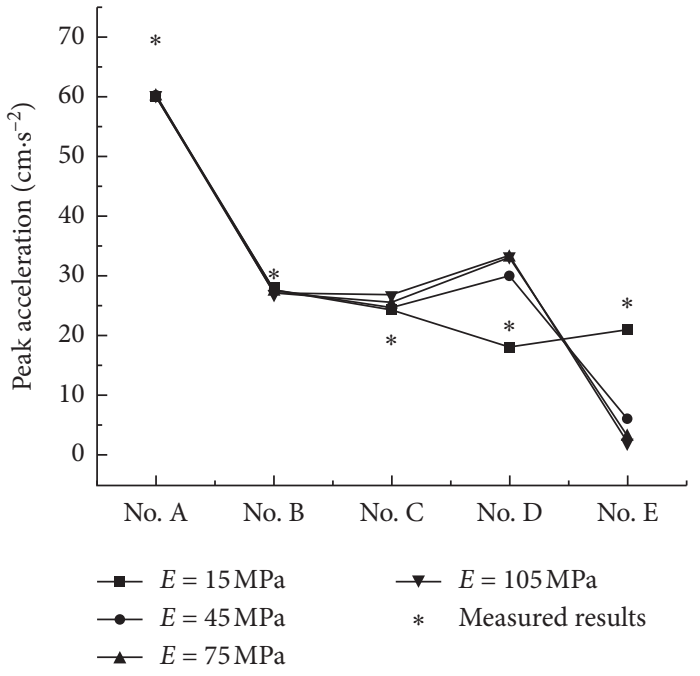

(a)

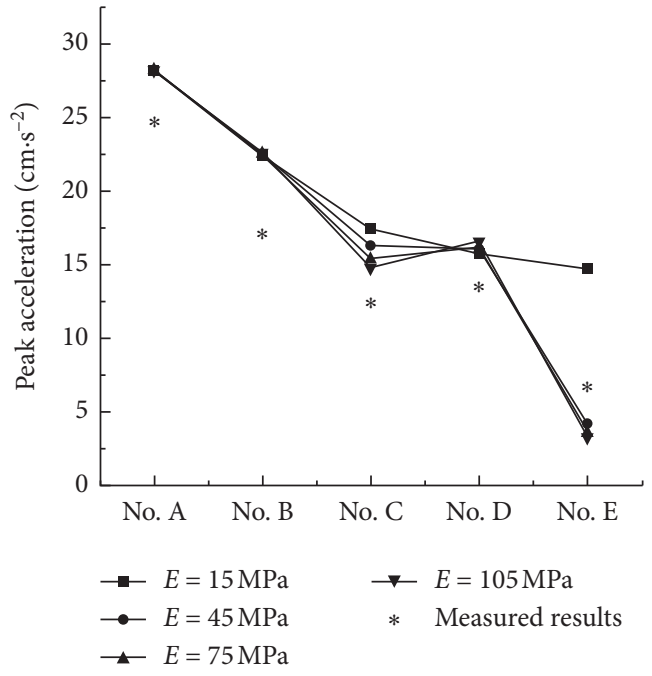

(b)

Figure 18: Influence of the elastic modulus of the fifth terrace on vibration. (a) Horizontal direction. (b) Vertical direction.

peak values of acceleration at test points $\mathrm{B}, \mathrm{C}$, and $\mathrm{E}$ decrease, whereas there is little effect on the values at test points $\mathrm{A}$ and $\mathrm{D}$. There is basically no vibration rebound phenomenon. In the vertical direction, with the increase in the elastic modulus of the soil in the second terrace level, the peak acceleration at test points $\mathrm{B}$ and $\mathrm{D}$ decreases, whereas it increases at test points $\mathrm{A}, \mathrm{C}$, and $\mathrm{E}$. The peak acceleration at test points $\mathrm{C}$ and $\mathrm{E}$ clearly rebounds.

Figure 16 shows the effect of the elastic modulus of the soil of the third terrace on vibration propagation. With the increase in the elastic modulus of the soil in the third terrace level, the peak value of the horizontal acceleration at test point A increases, whereas the peak value of the horizontal acceleration at the other test points decreases. In the vertical direction, with the increase in the elastic modulus, the peak acceleration at test points $\mathrm{B}$ and $\mathrm{E}$ increases, whereas the peak acceleration at test points $\mathrm{C}$ and $\mathrm{D}$ decreases. The peak acceleration at test points $\mathrm{B}$ and $\mathrm{D}$ rebounds. However, the change in the elastic modulus has little effect on the peak value of the vertical acceleration at test point $A$.

Figure 17 shows the effect of the elastic modulus of the soil of the fourth terrace on vibration propagation. With an increase in the elastic modulus in the horizontal direction, the peak acceleration at test point $B$ increases, whereas the peak acceleration at test points $\mathrm{C}$ and $\mathrm{E}$ decreases. The change in the elastic modulus has little effect on the peak value of the horizontal acceleration at test points $A$ and $D$. In the vertical direction, with an increase in the elastic modulus, the peak values of the acceleration at test points $B, D$, and $\mathrm{E}$ decrease, whereas the peak value of the acceleration at test point $C$ increases, and the peak values of acceleration at test points $\mathrm{C}$ and $\mathrm{D}$ show evident amplification. However, the peak value of the vertical acceleration at test point $\mathrm{A}$ is not affected by the change in the elastic modulus. 
Figure 18 shows the effect of the elastic modulus of the soil of the fifth terrace field on vibration propagation. In both the horizontal and vertical directions, the change in the elastic modulus has little effect on the peak acceleration at test points A and B. With an increase in the elastic modulus of the soil at the fifth terrace level, the peak value of the horizontal acceleration at test points $\mathrm{C}$ and $\mathrm{D}$ increases, and the peak value of the horizontal acceleration at test point $\mathrm{D}$ shows a more evident rebound, whereas the peak value of the acceleration at test point $\mathrm{E}$ decreases. In the vertical direction, with the increase in elastic modulus, the peak acceleration at test points $\mathrm{C}$ and $\mathrm{E}$ decreases, and the rebound of the peak acceleration at test point $\mathrm{D}$ becomes more evident. Soil samples were not taken at the test site for experiments, and the parameters of soil in the numerical model were taken from the relevant literature. Owing to the deviation between the data of the relevant literature and the field soil, the numerical simulation value is slightly different from the measured value. However, the change law is consistent, demonstrating that the numerical model is correct and feasible.

This analysis shows that a change in the elastic modulus of the foundation soil has a great influence on the horizontal and vertical vibrations in each terrace. With an increase in the elastic modulus of the foundation soil, the peak value of the horizontal acceleration at each test point decreases, and the vertical vibration at test point $B$ shows an evident amplification. The change in the elastic modulus of the soil at each terrace level has a clear influence on the horizontal and vertical vibrations of the two adjacent terraces. With the increase in the elastic modulus of the terrace level, the peak values of the horizontal and vertical accelerations at the edge of the terrace level decrease rapidly, and the peak values of horizontal and vertical acceleration at the edge of the lower and the higher terrace levels increase. This has little effect on the peak values of acceleration farther from the terrace level.

\section{Discussion and Conclusions}

A series of field measurements of the vibrations induced by high-speed trains at a terraced slope in a loess site near the Qin'an Railway Station of the Baoji-Lanzhou High-Speed Rail, China, were presented. Furthermore, the influences of changes in the soil mechanical parameters of the foundation and of each terrace on vibration propagation were analyzed. The measurements are complementary to available published data and provide not only a direct insight into the main features of the dynamic behavior of a loess-terraced slope but also a reference for slope prevention along a railway.

Through the analysis of test data in the time and frequency domains, it was found that the peak acceleration in the $Y$ direction was the largest, followed by those in the $X$ and $Z$ directions, under the action of a train load at the edge of each terraced level on the embankment section. At the edge of the fourth terrace level, the peak acceleration in the three directions clearly rebounded, and the peak acceleration in the $Y$ direction also rebounded at the edge of the fifth terrace level. The vibration frequencies in the three directions were concentrated at $10-80 \mathrm{~Hz}$. As one moved farther from the track center, the main frequency of vibration shifted toward a lower frequency; however, in the fourth and fifth terrace levels, the main frequency of vibration shifted toward a slightly higher frequency.

The $a_{\max }$ (peak acceleration) and VAL values at the edge of the first three terrace levels increased with the increase in train speed, yet no clear relationship was observed between the peak acceleration and VAL at the edges of the fourth and fifth terrace levels and the train speed, owing to the amplification effect of the vibration.

Numerical simulations showed that, with an increase in the elastic modulus of the foundation soil, the peak value of the horizontal acceleration decreased, but the peak value of the vertical acceleration at test point B increased, thereby demonstrating an evident amplification phenomenon. An increase in the elastic modulus of the soil in a terrace reduced the peak acceleration in that terrace but increased the peak values of the horizontal and vertical accelerations at the nearby terraces (i.e., below and above the considered terrace). However, little effect was seen on the terraces located farther away.

\section{Data Availability}

The data used to support the findings of this study are available from the corresponding author upon request.

\section{Conflicts of Interest}

The authors declare that they have no conflicts of interest.

\section{Authors' Contributions}

Wujian Yan contributed to field test, writing of the original draft, formal analysis, and writing, review, and editing of the paper. Haizhong Zheng, Tong Wan, Xinxin Tian contributed to field test and data curation. Zhijian $\mathrm{Wu}$ contributed to conceptualization, methodology, formal analysis, and writing, review, and editing of the paper.

\section{Acknowledgments}

Financial support for this project was provided by the Scientific Research Fund of Institute of Earthquake Forecasting, China Earthquake Administration (Grant nos. 2014IESLZ01 and 2015IESLZ05), the Second Tibetan Plateau Scientific Expedition and Research Program (STEP) (Grant no. 2019QZKK0905), Scientific Research Fund of Institute of Engineering Mechanics, China Earthquake Administration (Grant no. 2020 EEEVL0304), the National Natural Science Foundation of China (Grant nos. 51678545, 41472297, and U1939209), and Topics of the National Key R\&D Program (Grant no. 2017YFC1500906).

\section{References}

[1] M. Tokunaga, M. Sogabe, T. Santo, and K. Ono, "Dynamic response evaluation of tall noise barrier on high speed railway 
structures," Journal of Sound and Vibration, vol. 366, pp. 293-308, 2016.

[2] S. Hesami, S. Ahmadi, and A. T. Ghalesari, "Numerical modeling of train-induced vibration of nearby multi-story building: a case study," KSCE Journal of Civil Engineering, vol. 20, no. 5, pp. 1701-1713, 2016.

[3] S. Drabkin, H. Lacy, and D. S. Kim, "Estimating settlement of sand caused by construction vibration," Journal of Geotechnical Engineering, vol. 122, no. 11, pp. 920-928, 1996.

[4] D. S. Kim and J. S. Lee, "Propagation and attenuation characteristics of various ground vibrations," Soil Dynamics and Earthquake Engineering, vol. 19, no. 2, pp. 115-126, 2000.

[5] X. Sheng, C. J. C. Jones, and D. J. Thompson, "A theoretical study on the influence of the track on train-induced ground vibration," Journal of Sound and Vibration, vol. 272, no. 3-5, pp. 909-936, 2004.

[6] X. Sheng, C. J. C. Jones, and D. J. Thompson, "A theoretical model for ground vibration from trains generated by vertical track irregularities," Journal of Sound and Vibration, vol. 272, no. 3-5, pp. 937-965, 2004.

[7] J. A. Forrest and H. E. M. Hunt, "Ground vibration generated by trains in underground tunnels," Journal of Sound and Vibration, vol. 294, no. 4-5, pp. 706-736, 2006.

[8] Y. P. Wang, B. Y. Sun, Q. Li et al., “A numerical model for ground-borne vibrations from underground railway traffic based on a periodic finite element-boundary element formulation," Journal of Sound and Vibration, vol. 293, no. 3, pp. 645-666, 2006.

[9] H. H. Hung, G. H. Chen, and Y. B. Yang, "Effect of railway roughness on soil vibrations due to moving trains by $2.5 \mathrm{D}$ finite/infinite element approach," Engineering Structures, vol. 57, pp. 254-266, 2013.

[10] N. Triepaischajonsak and D. J. Thompson, "A hybrid modelling approach for predicting ground vibration from trains," Journal of Sound and Vibration, vol. 335, pp. 147-173, 2015.

[11] K. K. Ang and J. Dai, "Response analysis of high-speed rail system accounting for abrupt change of foundation stiffness," Journal of Sound and Vibration, vol. 332, no. 12, pp. 29542970, 2013.

[12] H. Xia, N. Zhang, and Y. M. Cao, "Experimental study of train-induced vibrations of ground and nearby buildings," Journal of the China Railway Society, vol. 26, no. 4, pp. 93-98, 2004, in Chinese.

[13] G. Y. Gao, Z. Y. Li, S. J. Feng et al., "Experimental results and numerical predictions of ground vibration induced by highspeed train running on Qin-Shen Railway," Rock and Soil Mechanics, vol. 28, no. 9, pp. 1817-1822, 2007, in Chinese.

[14] X. L. Meng and F. J. Zhou, "Spatial analysis and study of roadbed vibration effect on loess area for Xi'an Baoji high speed railway," Journal of Railway Engineering Society, vol. 34, no. 8, pp. 28-33, 2017, in Chinese.

[15] Z. Y. WangX. C. Ling et al., "Field monitoring of vibration response of subgrade in a seasonally frozen region," Chinese Journal of Geotechnical Engineering, vol. 37, no. 9, pp. 15911598, 2015, in Chinese.

[16] Z. J. Wu, T. Chen, and W. Ma, “The creep analysis of plain fill embankment at the permafrost regions along Qinghai-Tibet Railway under train dynamic load," Rock and Soil Mechanics, vol. 32, no. 2, pp. 83-87, 2011, in Chinese.

[17] Z. J. Wu, T. Chen, and W. Ma, "Characteristics of load transmission of trains in permafrost regions along QinghaiTibet railroad," Chinese Journal of Geotechnical Engineering, vol. 35, no. S1, pp. 9-13, 2013, in Chinese.
[18] G. Lombaert, G. Degrande, J. Kogut, and S. François, "The experimental validation of a numerical model for the prediction of railway induced vibrations," Journal of Sound and Vibration, vol. 297, no. 3-5, pp. 512-535, 2006.

[19] K. F. Li, W. N. Liu, X. J. Sun, Z. K. Wang, and W. B. Wang, "In-situ test and analysis on the vibration mitigation measures of the elevated line in Beijing metro line 5," China Railway Science, vol. 30, no. 4, pp. 25-29, 2009, in Chinese.

[20] G. Degrande and L. Schillemans, "Free field vibrations during the passage of a thalys high-speed train at variable speed," Journal of Sound and Vibration, vol. 247, no. 1, pp. 131-144, 2001.

[21] X. Ling, F. Zhang, Z. Zhu, L. Ding, and Q. Hu, "Field experiment of subgrade vibration induced by passing train in a seasonally frozen region of Daqing," Earthquake Engineering and Engineering Vibration, vol. 8, no. 1, pp. 149-157, 2009.

[22] G. Degrande, M. Schevenels, P. Chatterjee et al., "Vibrations due to a test train at variable speeds in a deep bored tunnel embedded in London clay," Journal of Sound and Vibration, vol. 293, no. 3-5, pp. 626-644, 2006.

[23] J. Vega, A. Fraile, E. Alarcon, and L. Hermanns, "Dynamic response of underpasses for high-speed train lines," Journal of Sound and Vibration, vol. 331, no. 23, pp. 5125-5140, 2012.

[24] W. Fu, "Distribution rules of collapsible loess and analysis on foundation treatment technology on Baoji-lanzhou passenger dedicated line," Railway Standard Design, vol. 58, no. 11, pp. 15-19, 2014, in Chinese.

[25] L. H. Ma, "Research on vibration of shanghai-nanjing intercity high-speed railway and its environmental impact," Doctoral dissertation, Beijing Jiao University, Beijing, China, 2015.

[26] State Environmental Protection Administration, GB10071988 Measurement Method of Environment Vibration of Urban area, Standards Press of China, Beijing, China, 1989, in Chinese.

[27] Z. P. Liao, Introduction to Wave Motion Theories in engineering, 2nd edition, pp. 190-227, Science Press, Beijing, China, 2002, in Chinese.

[28] B. Liang, H. Luo, and C. X. Sun, "Simulation of vibration load on high speed railway," Journal of the China Railway Society, vol. 28, no. 4, pp. 89-94, 2006, in Chinese.

[29] H. X. Lu, L. Y. Xu, P. Y. Liang, and B. T. Wu, "Influence of hill on railway environmental vibration," Rock and Soil Mechanics, vol. 40, no. 4, pp. 1561-1568, 2019, in Chinese.

[30] L. An, J. Deng, P. Guo et al., "Correlation between microscopic parameters and dynamic elastic modulus of loess," Chinese Journal of Geotechnical Engineering, vol. 41, no. 2, pp. 105-108, 2019, in Chinese.

[31] T. F. Gu, J. D. Wang, Q. Ren et al., "Study on deformation of loess slope under cyclic load," Chinese Journal of Rock Mechanics and Engineering, vol. 28, no. 1, pp. 3156-3162, 2009, in Chinese. 